Review

\title{
Marine Antimalarials
}

\section{Ernesto Fattorusso and Orazio Taglialatela-Scafati *}

Dipartimento di Chimica delle Sostanze Naturali, Università di Napoli "Federico II", Via D. Montesano, 49, I-80131, Napoli, Italy. E-Mail: fattoru@unina.it

* Author to whom correspondence should be addressed. E-Mail: scatagli@unina.it

Received: 7 April 2009; in revised form: 20 April 2009 / Accepted: 22 April 2009 /

Published: 23 April 2009

\begin{abstract}
Malaria is an infectious disease causing at least 1 million deaths per year, and, unfortunately, the chemical entities available to treat malaria are still too limited. In this review we highlight the contribution of marine chemistry in the field of antimalarial research by reporting the most important results obtained until the beginning of 2009, with particular emphasis on recent discoveries. About 60 secondary metabolites produced by marine organisms have been grouped into three structural types and discussed in terms of their reported antimalarial activities. The major groups of metabolites include isonitrile derivatives, alkaloids and endoperoxide derivatives. The following discussion evidences that antimalarial marine molecules can efficiently integrate the panel of lead compounds isolated from terrestrial sources with new chemical backbones and, sometimes, with unique functional groups.
\end{abstract}

Keywords: Malaria, Marine metabolites, Isonitrile, Alkaloids, Endoperoxides

\section{Introduction}

Malaria is an infectious disease caused by several protozoans belonging to the genus Plasmodium (P. falciparum, P. ovale, P. vivax, P. malariae), with P. falciparum (Pf) being the parasite responsible for most severe diseases and most fatal cases. The protozoan comes in contact with humans through the vector contribution of female mosquitoes of the genus Anopheles, then it invades red blood cells causing anaemia; the ensuing rupture of infected erythrocytes is associated with the release into the 
blood stream of cell debris responsible for the characteristic fever spike patterns. In lethal cases, a specific protein produced by the protozoan is embedded into the cell membrane of the infected erythrocyte and, as a consequence of this modification, the erythrocyte sticks to the walls of capillaries causing obstruction of vessels. When this mechanism operates at the level of brain vessels, the loss of consciousness is the first symptom, but, if this form of cerebral malaria is not treated immediately, it is soon followed by death.

The improvement of hygienic conditions, the massive use of insecticides, and the discovery of different drugs played a great role in the nearly complete extinction of infections registered in developed countries. Unfortunately, in the tropical countries of Africa, Asia and America, malaria is still a common cause of death (each year, 300-500 million people become ill with malaria and 1-3 million die) and tragically most of the victims are children under the age of five: every 30 seconds a child dies of malaria [1]. A troublesome increase in the number of fatal cases has been registered in recent years and this is principally due to the spread of multi-drug resistant strains of Plasmodium, that make ineffective the limited armamentarium of drugs now available. Since malaria is a disease of worldwide implications and almost half of the world's population is currently at risk for malaria infection, combating malaria is one of the highest priority programs of WHO [2].

Unfortunately, in spite of several years of efforts and a number of announcements, a vaccine against malaria has not yet been found and the number of different strains causing the pathology and their tendency to genetic mutations promise to create difficulties to this strategy also in the future. Moderate optimism has recently been arisen by RTS,S vaccine, heading phase III trials in 2009, but its potential protective efficacy has been estimated not higher than $30 \%-40 \%$ and only when the vaccine is used in combination with an effective adjuvant therapy [3].

On the other hand, the impressive progresses in the field of genetic research have allowed the sequencing of the entire genome of both the malarial parasite and its insect vector; this important result disclosed a host of pharmaceutical targets to prevent and/or treat the disease [4]. Therefore, the pharmacological therapy has been in the past and currently remains the best answer that researchers have proposed against malaria. Unfortunately, the number of drugs active against malaria continues to be very small and the selection of resistant strains is further narrowing the number of effective molecules. In the last 30 years about 1,700 new drugs have been registered and, among them, only 15 were destined to tropical diseases and only 4-5 against malaria. This picture dramatically illustrates the unquestionable evidence that efforts of pharmaceutical companies are obviously not proportional to the number of deaths for a certain pathology but mostly to the potential market of the developed drugs.

Figure 1. Chloroquine (1) and mefloquine (2)
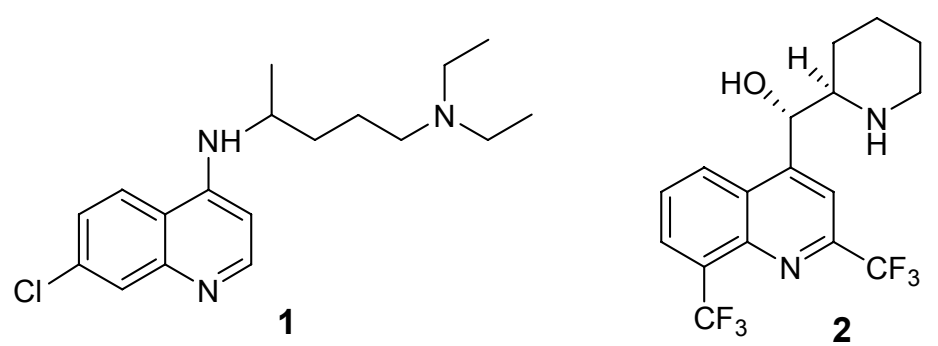
The available chemical entities to treat malaria cases are sadly based on very old molecules, like the chloroquine analogues (Figure 1). Although the combination of these molecules with artemisinin and other endoperoxide analogues is giving some good results, the therapeutic choices are still too limited. There is therefore an urgent need for new and innovative drugs. According to Jefford, a drug directed against plasmodium should be active orally for 1-3 days, should give a fast eradication of parasite and disappearance of symptoms, should be safe for children and pregnant women, and, more importantly, should be as cheap as aspirin $(<1 €$ per treatment) [5].

To reach this challenging aim, the identification and selection of new lead compounds constitutes a crucial point. In this regard, living organisms are a recognized source of potentially bioactive molecules which are, commonly, more effective than those obtained through combinatorial synthetic chemistry. Indeed, synthetic libraries are straightforward to assemble, this representing an advantage but also a drawback: the use of a relatively limited number of synthetic reactions as well as of structurally diverse building blocks to library construction implies that combinatorial libraries often lack the structural diversity required for fully exploring the biological space. On the other hand, having been enzymatically engineered and biologically validated, the "quality" of both terrestrial and marine natural products is higher and they represent the ideal tool to harvest the fruits encrypted in a genomic text.

Thus, not surprisingly, the most significant advancements in malaria therapy have been made with the introduction of natural leads. The treatment of malaria infections holds a venerable place both in the history of medicinal chemistry and of natural product chemistry. Indeed, malaria was the first disease to be treated with an active principle isolated from a natural source, quinine, isolated from the Cinchona bark in 1820 , and until the $20^{\text {th }}$ century many of the active medicines were developed based on the structure of quinine. A more recent breakthrough in the fight against malaria came with the discovery of artemisinin, an endoperoxide sesquiterpene from Artemisia annua [6], an herbal remedy used in Chinese folk medicine. It is now expected that the next significant advancement in the field of antimalarial drugs will not be reached through the discovery of a single potent compound, but through the introduction of an innovative drug to be used in a combined therapy, preferably composed by molecules acting at different stages of the malaria parasite life cycle.

Hopefully, the new breakthrough in the malaria treatment will come with the development of a marine lead compound. The incredible potential of even a single marine organism (mostly invertebrates, as sponges, tunicates, soft corals) to produce a large array of secondary metabolites can be interpreted by considering the common features of the secondary metabolism in all the living organisms as well as some peculiar features of the marine environment. In addition, the contribution of the symbiotic population to the metabolic work of a marine invertebrate is an important point to be taken into account. Indeed, marine invertebrates harbor in their tissues a series of microorganisms such as bacteria, cyanobacteria and fungi and, in some cases, associated micro-organisms may constitute up to $40 \%$ of the biomass $[7,8]$, this bacterial concentration exceeding that of the surrounding sea water by two or three orders of magnitude. Although the real contribution of the microorganisms to the secondary metabolism of marine invertebrates has not yet been fully evaluated, essentially because of the difficulties encountered in culturing sponge-associated bacteria, it is generally accepted that these harbored microorganisms play a significant role in the biosynthesis of the natural products isolated from the invertebrate. Furthermore, the recent impressive advances in molecular genetics, currently 
allowing the identification of biosynthetic genes in the producing organisms and their cloning in bacteria suitable for large-scale fermentation [9] could represent a solution for the problem of compound supply. If these techniques will be fully developed and utilized, the last obstacle to consider marine organisms as a potentially sustainable drug source would be overcome.

This review aims at highlighting the contribution of marine chemistry in the field of antimalarial research, by reporting the most important results obtained until the beginning of 2009, with particular emphasis on recent discoveries. We have decided to include in this review all those compounds possessing a moderate to high antimalarial activity, thus excluding very weak antimalarials or molecules for which the toxicity toward Plasmodium strains is not specific and/or is clearly due to a general cytotoxicity. An interesting review has been recently published focusing on the synthesis of marine natural products with antimalarial activity [10]; consequently, we will not discuss in detail synthetic efforts aimed at preparing marine antimalarial leads.

Following a scheme that we have introduced in a recent book chapter [11], marine antimalarials have been divided throughout this review, according to their chemical structures, into three different classes: i) isonitrile-containing derivatives; ii) alkaloids; iii) endoperoxides. A paragraph including miscellaneous compounds not belonging to the above classes is presented at the end of the review.

\section{Isonitrile-containing derivatives and their analogues}

The parent compound of the small class of isonitrile-containing marine secondary metabolites is axisonitrile-1 (3, Figure 2), isolated in 1973 from the marine sponge Axinella cannabina, where it cooccurred with the strictly related axisothiocyanate-1 (4) [12]. Axisonitrile-1 was soon followed by other isonitrile-, isothiocyanate-, and formamide-containing sesquiterpenoids from the same source, namely axamide-1 (5), axisonitrile-2, (6) [13], axisothiocyanate-2 (7), axamide-2 (8) [14], axisonitrile3 (9), axisothiocyanate-3 (10), and axamide-3 (11) [15] (Figure 2).

Figure 2. Isonitrile-, isothiocyanate- and formamide-containing sesquiterpenoids from the sponge Axinella cannabina.
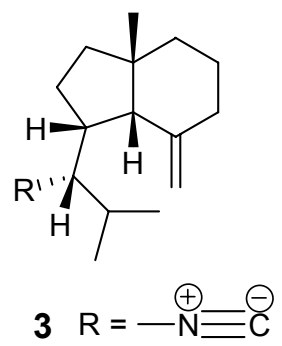

$4 \mathrm{R}=-\mathrm{N}=\mathrm{C}=\mathrm{S}$

$5 \mathrm{R}=-\underset{\mathrm{H}}{\mathrm{N}}-\stackrel{\mathrm{C}}{\mathrm{H}}=\mathrm{O}$

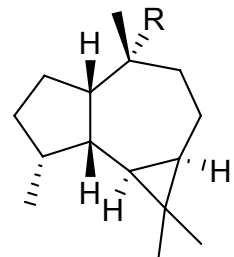

$6 \mathrm{R}=-\stackrel{\oplus}{\mathrm{N}} \equiv \stackrel{\ominus}{=}$

$7 \mathrm{R}=-\mathrm{N}=\mathrm{C}=\mathrm{S}$

$8 R=-\underset{1}{N}-\mathrm{C}=\mathrm{I}$

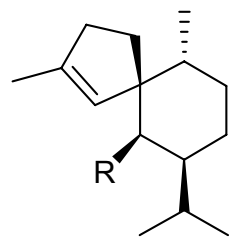

$9 \mathrm{R}=\stackrel{\oplus}{\mathrm{N}}=\stackrel{\mathrm{E}}{\mathrm{C}}$

$10 \mathrm{R}=-\mathrm{N}=\mathrm{C}=\mathrm{S}$

$11 R=-\underset{1}{-}-\underset{1}{H} \quad$ H

The chemical structure of these derivatives has been confirmed by elegant syntheses, including the very recent total synthesis of axamide-1 and axisonitrile-1 via 6-exo-dig radical cyclization [16]. In 1992, axisonitrile-3 (9) was re-isolated from the sponge Acanthella klethra Pulitzer-Finali and found to possess a potent antimalarial activity both on chloroquine-sensitive (D6, $142 \mathrm{ng} / \mathrm{mL}$ ) and chloroquine- 
resistant (W2, $17 \mathrm{ng} / \mathrm{mL}$ ) P. falciparum strains [17], and to be practically devoid of cytotoxicity toward KB cells. The closely related axisothiocyanate-3 (10) was inactive, suggesting that the antiplasmodial activity should not (or, at least, not only) be ascribed to structural features of the carbon backbone but should be strictly dependent on the presence of the isonitrile functional group.

These remarkable findings stimulated an in-depth research activity aimed at isolating and testing isonitrile secondary metabolites from different marine sources, with particular regards to marine sponges of the families Axinellidae and Halicondridae appearing to selectively elaborate these kinds of metabolites. The chemical analysis of the sponge Cymbastela hooperi (Axinellidae) afforded a series of diterpenes based on amphilectane, isocycloamphilectane, and neoamphilectane skeletons and bearing isonitrile, isothiocyanate, and the rare isocyanate functionalities (Figure 3) [18]. These molecules displayed a significant (low $\mathrm{nM}$ range) and selective (cytotoxicity in the $\mu \mathrm{M}$ range) in vitro antimalarial activity and the co-occurrence of several strictly related analogues suggested some structure-activity relationships.

Figure 3. Representative isonitrile- and isothiocyanate-containing diterpenoids isolated from the marine sponge Cymbastela hooperi.

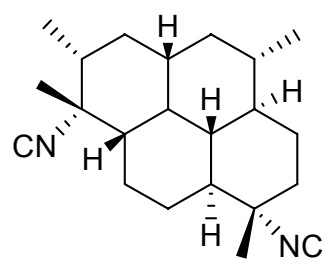

12

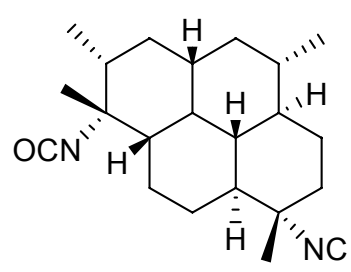

15

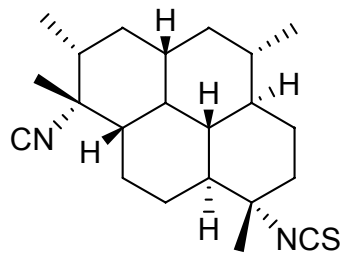

13<smiles>C=C(C)CC1C[C@H](C)C2CC[C@](C)(C#N)[C@H]3CCC(=C)C1[C@H]23</smiles>

16

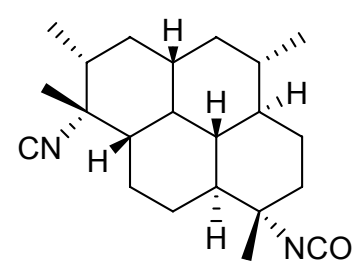

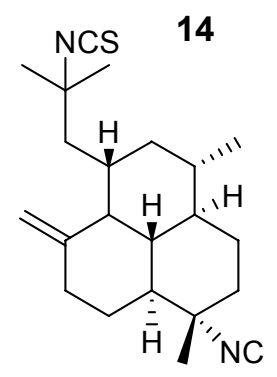

17

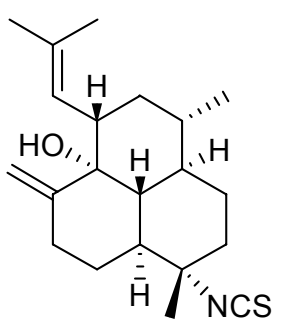

18

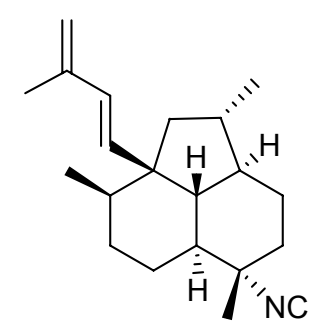

19

Comparison among the activities exhibited by the closely related isocycloamphilectanes $\mathbf{1 2}\left(\mathrm{IC}_{50} \sim\right.$ $4 \mathrm{ng} / \mathrm{mL}), 13\left(\mathrm{IC}_{50} \sim 40 \mathrm{ng} / \mathrm{mL}\right)$, and 14 ( $\left.\mathrm{IC}_{50} \sim 60 \mathrm{ng} / \mathrm{mL}\right)$ illustrated the relative potency of isonitrile, isothiocyanate and isocyanate groups, supporting the previous observation that the bioactivity is particularly associated to the presence of the isonitrile group. However, the location of functional 
groups also plays a role, as suggested by the comparison between the activities of compounds $\mathbf{1 4}$ and 15 ( $\mathrm{IC}_{50} \sim 3 \mathrm{ng} / \mathrm{mL}$ ), where the positions of isocyanate and isonitrile groups are interchanged.

The importance of the isonitrile group is highlighted by the relatively low activity of the amphilectane isothiocyanate $18\left(\mathrm{IC}_{50} \sim 800 \mathrm{ng} / \mathrm{mL}\right)$, and by the similarly low activity of amphilectane formamides, very recently isolated from the same source [19]. On the other hand, the activity of the neoamphilectane derivative $19\left(\mathrm{IC}_{50}=\mathrm{D} 6,90 \mathrm{ng} / \mathrm{mL} ; \mathrm{W} 2,30 \mathrm{ng} / \mathrm{mL}\right)$ is considerably higher than that of compound 16, indicating that the carbon skeleton can modulate the antiplasmodial activity of isonitrile derivatives.

Further isonitrile-containing antimalarial derivatives have been isolated from the Japanese sponge Acanthella sp. (e.g. 20-21, Figure 4) [20]. These molecules belong to the class of the kalihinane diterpenoids, which comprises also antifungal, anthelmintic and antifouling compounds. Isonitrile kalihinanes showed a potent antiplasmodial activity in the very low nanogram range [e.g. kalihinol A (21) $\mathrm{IC}_{50}=0.4 \mathrm{ng} / \mathrm{mL}$. A total synthesis of a kalihinol A analogue has been accomplished [21].

Figure 4. Representative kalihinane diterpenoids isolated from the marine sponge Acanthella sp.

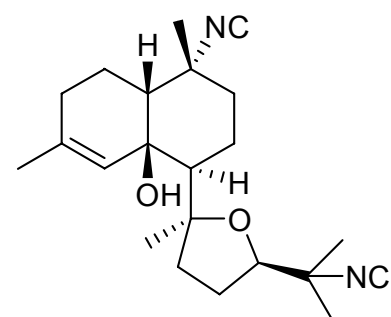

20

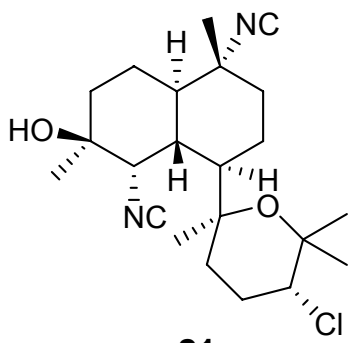

21

A hybrid modelling technique combining 3D-QSAR with quasi-atomistic receptor modelling methodologies has been used to generate a pharmacophore hypothesis for isonitrile derivatives consistent with the experimental bioactivities, indicating a likely mechanism of action for this class of marine antimalarials [22]. Active isonitriles were demonstrated to interact with free heme by forming a coordination complex with the iron center; the "pharmacophore" must possess an overall lipophilic rigid molecular core comprising at least a tricyclic framework carrying an isonitrile group and establishing further hydrophobic interactions above the ring plane. Interaction of marine isonitriles derivatives with heme could inhibit the transformation of heme into $\beta$-hematin and then hemozoin, a polymer produced by Plasmodium in order to neutralize the toxic (detergent-like) free heme produced in the food vacuole. In addition, isonitriles were shown to prevent both the peroxidative and glutathione-mediated destruction of heme under conditions that mimic the environment within the malaria parasite. Thus, isonitriles exert their antiplasmodial activity by preventing heme detoxification [22].

\section{Alkaloids}

Manzamines are undoubtedly the most important and potent antimalarial alkaloids isolated from marine sources. They are very complex polycyclic (7-8 rings or more) alkaloids first reported by Higa and coworkers in 1986 from an Okinawan sponge belonging to the genus Haliclona [23,24]. These 
molecules are characterized by an intricate pentacyclic heterocyclic system attached to a $\beta$-carboline moiety. Since the first report of manzamine A (22, Figure 5), at least 60 additional manzamine-type alkaloids have been reported from taxonomically unrelated sponges belonging to different genera (e.g. Xestospongia, Ircinia, and Amphimedon) and different orders. These findings strengthen the hypothesis that manzamines are not true sponge metabolites but, more likely, they have a symbiotic origin. Accordingly, microbial community analyses for one of the most common manzamine producing sponges resulted in the identification of Micronosphora $\mathrm{sp}$. as the bacteria producing manzamines [25]. A recent paper hypothesized a common biosynthetic route for cyclostellettamines, halicyclamines and manzamines, thus highlighting the existence of "nature diversity-oriented syntheses" [26].

Figure 5. Chemical structure of manzamine A (22) and manzamine F (23)

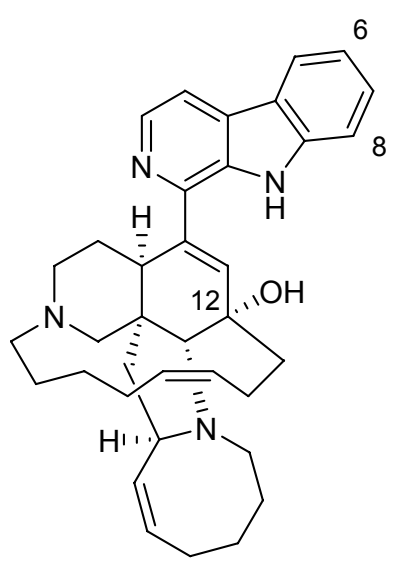

22

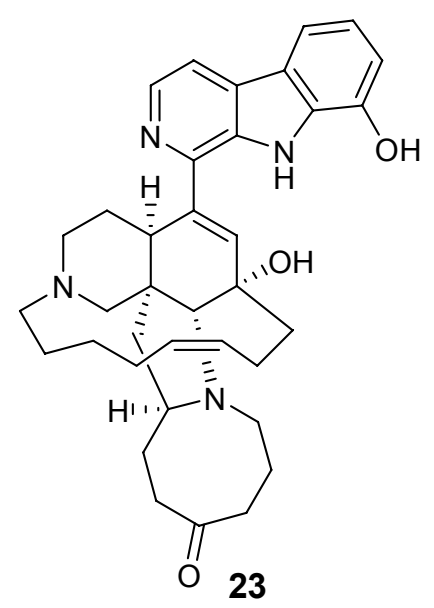

Fourteen years after its first isolation, Hamann et al. disclosed the antimalarial potential of manzamine A [27]. This molecule, and its 8-hydoxy derivative, were found to potently inhibit the growth of Plasmodium falciparum both in vitro $\left(\mathrm{IC}_{50} \sim 5.0 \mathrm{ng} / \mathrm{mL}\right.$ ) and in vivo (a parasitemia suppression of the same order of magnitude of that of artemisinin). Unfortunately, the therapeutic index of these molecules is somewhat narrow (gastrointestinal distress) and further studies are needed to improve this value.

Interestingly, a closely related derivative of manzamine A, manzamine $\mathrm{F}$ (23, Figure 5), is completely devoid of activity $\left(\mathrm{IC}_{50}>1,000 \mathrm{ng} / \mathrm{mL}\right.$ ), thus evidencing the key role of the eight membered ring, where the differences between the inactive manzamine $\mathrm{F}$ and the active manzamine $\mathrm{A}$ are confined. The reduction of the double bond and/or the insertion of a ketone group on the adjacent carbon is evidently deleterious for the antimalarial activity. Similarly, the attachment of the hydroxyl group at position 6 , in place of position 8 , has a deleterious impact on the antimalarial activity, as indicated by the lower potency of manzamine $\mathrm{Y}$ (6-hydroxy-manzamine A), exhibiting $\mathrm{IC}_{50} \sim 600$ $\mathrm{ng} / \mathrm{mL}[28]$.

Additional information on structure-activity relationships came with the isolation of neokauluamine (24, Figure 6) a very complex molecule constituted by two manzamine units dimerized through ether linkages between the eight-membered rings [29]. Although this molecule, like manzamine F (23), lacks the double bond in the eight-membered ring, it demonstrated the same 
antimalarial activity as manzamine $\mathrm{A}$. The lack of antimalarial activity for 12,34-oxamanzamine A (25, Figure 6) $\left(\mathrm{IC}_{50}=5 \mu \mathrm{g} / \mathrm{mL}\right)$ [30] indicates that the C-12 hydroxyl, the C-34 methine or the conformation of the eight-membered ring are of key importance for the antimalarial activity. The crucial role of the hydroxy group at position 12 has also been highlighted by a recent study reporting that acetylation at position 12 significantly reduced the antimalarial activity [31].

Figure 6. Chemical structures of neo-kauluamine (24) and 12,34-oxamanzamine A (25).

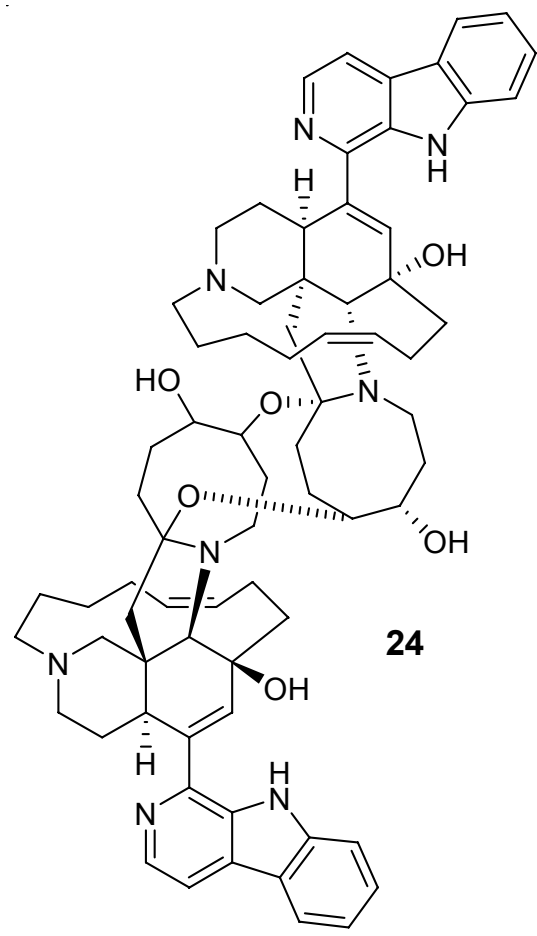

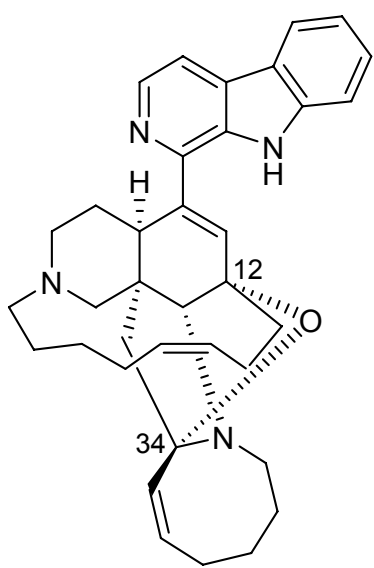

25

Manzamines have also been reported to be antiinflammatory, antifungal, antibacterial and antitubercolosis agents, and to exhibit activity against AIDS opportunistic pathogens (e.g. Toxoplasma gondii) [29, 32, 33]. More recently, inhibitory activity against glycogen synthase kinase-3 (GSK-3) has been discovered for manzamine $\mathrm{A}$ and derivatives [34]. The inhibited kinase is involved in pathological hyperphosphorylation of protein tau and, therefore, manzamine A constitutes a promising scaffold to design potential therapeutic agents for Alzheimer's disease. The highly complex structure of manzamines have made them an attractive total synthesis target, and three different total syntheses have been published [35-37].

Figure 7. Chemical structure of homofascaplysin A (26)<smiles>CC(=O)CC1(O)c2ccccc2-[n+]2ccc3c([nH]c4ccccc43)c21</smiles>

26

The $\beta$-carboline group is also present in the structure of homofascaplysin A (26, Figure 7), isolated from the sponge Hyrtios erecta [38]. This alkaloid showed activity against chloroquine-resistant $P$. 
falciparum strains with an $\mathrm{IC}_{50}$ of about $20 \mathrm{ng} / \mathrm{mL}$, but its toxicity toward rat skeletal muscle myoblast cells was estimated to be less than $1 \mu \mathrm{g} / \mathrm{mL}$.

Lepadins are decahydroquinoline derivatives bearing a linear eight-carbon chain obtained from two marine invertebrates of Australian origin, Clavelina lepadiformis [39] and Didemnum sp. [40]. Lepadin E (29, Figure 8) exhibited a significant antimalarial activity $\left(\mathrm{IC}_{50}=400 \mathrm{ng} / \mathrm{mL}\right)$ while its close analogues lepadin B (27) and D (28) (Figure 8) are almost completely inactive. This marked difference of activity highlights the importance of the $2 E$-octenoic acid ester functionality in place of the secondary alcohol. Authors have proposed that this conformationally mobile side-chain could serve to stabilize non-bonding interactions with heme, or with any other "receptor" molecule. On the other hand, lepadin B has been found to block neuronal nicotinic acetylcholine receptors [41]. A number of total syntheses of lepadins have been accomplished [42].

Figure 8. Chemical structures of lepadins B (27), D (28) and E (29).

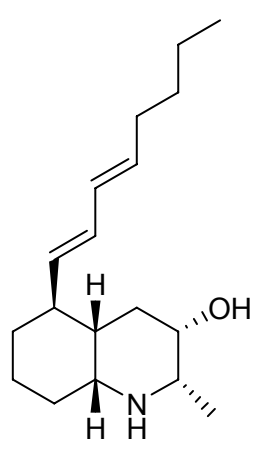

27

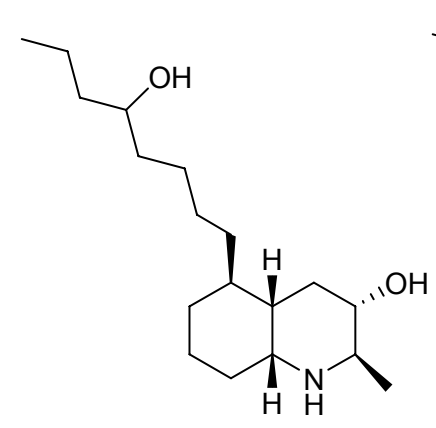

28

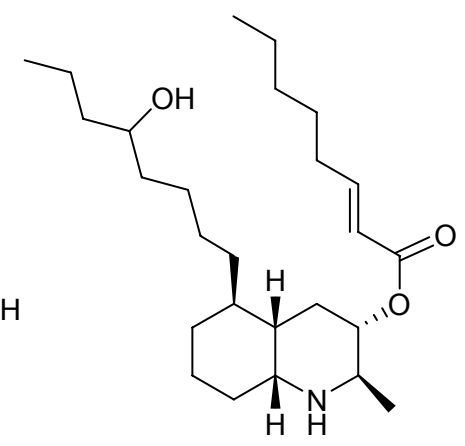

29

Phloeodictynes are a class of marine alkaloids whose chemical structure appears to be related to that of lepadins in having a bicyclic nitrogen-containing skeleton bearing a long alkyl chain. Phloeodictynes, isolated from sponges belonging to the genus Oceanapia [43, 44], are 1,2,3,4-tetrahydropyrrolo-[1,2-a]-pyrimidinium derivatives bearing at C-6, in addition to an $\mathrm{OH}$ group, a variablelength alkyl chain and at N-1 a four/five methylene chain ending in a guanidine group.

Phloeodictyn 5,7i (30, Figure 9) exhibited a good activity (IC50 $=300 \mathrm{ng} / \mathrm{mL}$ ) against the chloroquine-resistant FGB1 strain of the malaria parasite Plasmodium falciparum, with a good therapeutic index [44]. Total synthesis for these molecules has been reported [45].

Figure 9. Chemical structure of the active compound phloeodictyn 5,7i (30).

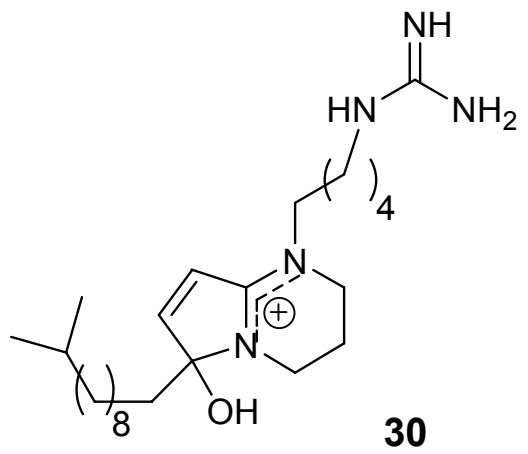


6-Bromoaplysinopsin (31, Figure 10) is a simple indole derivative first isolated in 1985 [46] and later re-obtained from the sponge Smenospongia aurea [47], active against the D6 clone of $P$. falciparum with $\mathrm{IC}_{50}=340 \mathrm{ng} / \mathrm{mL}$ and a low selectivity index. Heptyl prodigiosin (32, Figure 10) is a pigment, purified from a culture of $\alpha$-proteobacteria isolated from a marine tunicate, which showed an antimalarial activity similar to that of quinine against the chloroquine-sensitive strain $P$. falciparum 3D7 with an in vitro activity that was about 20 times the in vitro cytotoxic activity against mouse lymphocytes. When this molecule was tested in vivo, a single administration of $5 \mathrm{mg} / \mathrm{kg}$ significantly extended the survival of $P$. berghei ANKA strain-infected mice but, unfortunately, the same dose caused sclerotic lesions at the site of injection [48].

Figure 10. Chemical structures of 6-bromoaplysinopsin (31) and of heptylprodigiosin (32).<smiles>CN1C(=N)N(C)C(=Cc2c[nH]c3cc(Br)ccc23)C1=O</smiles><smiles>CCCCCCCC1=C/C(=C\c2[nH]c(-c3ccc[nH]3)cc2OC)N=C1C</smiles>

All the above marine alkaloids are characterized by a relatively poor knowledge of the mechanism of their antimalarial action, which is quite important to develop more potent and/or structurally simplified analogues. On the other hand, a couple of recently published antimalarial marine alkaloids have been found in the frame of investigations addressed against specific parasite targets.

Oroidin (33, Figure 11), the parent compound of a well-known class of marine alkaloids [49, 50], has been found to inhibit Plasmodium falciparum enoyl-ACP reductase $\left(\mathrm{IC}_{50}=0.30 \mu \mathrm{g} / \mathrm{mL}\right)$, an enzyme involved in the parasite fatty acid biosynthesis [51]. Further studies on the numerous oroidin analogues could reveal the structural requirements to interact with this target.

Salinosporamide A (34, Figure 11) is a $\gamma$-lactam alkaloid isolated from a marine bacterium of the new genus Salinispora [52]. This molecule has been found to be a potent parasite proteasome inhibitor and to possess a quite significant antimalarial activity in vitro $\left(\mathrm{IC}_{50}=11.4 \mathrm{nM}\right)$ [53]. Salinosporamide was determined to act in the erythrocytic stage and maintained its potent activity in a malaria mouse model with inhibition of the parasite growth in treated mice at extremely low doses $(130 \mu \mathrm{g} / \mathrm{kg})$.

Figure 11. Chemical structures of oroidin (33) and salinosporamide A (34).<smiles>Nc1nc(/C=C/CNC(=O)c2cc(Br)c(Br)[nH]2)c[nH]1</smiles>

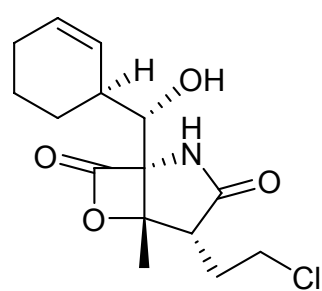

34 
Although some total syntheses of salinosporamide have been reported [54, 55], as for manzamine A, the bacterial origin of salinosporamide should provide opportunities for a renewable supply of the compound without harvesting large quantities of marine invertebrates. Anyway, in this case, also the relatively simple chemical structure of salinosporamide A could play in favour of the further development of this molecule as antimalarial drug.

\section{Endoperoxides}

One of the more substantial breakthroughs in malaria chemotherapy has been the discovery and development of endoperoxide-containing drugs. Research in this field began with the discovery that artemisinin (35, Figure 12), an endoperoxide cadinane sesquiterpene lactone possessing a 1,2,4trioxane moiety, isolated from Artemisia annua (Compositae) leaves, possessed nanomolar activity also against chloroquine-resistant strains of Plasmodium [6, 56]. With its unique juxtaposition of peracetal, acetal and lactone functionalities, artemisinin possesses structural features very appealing to organic chemists. Totally synthetic routes to artemisinin have been developed [57], but their complexity suggests that they will very unlikely supplant the natural extract as a drug supply.

Figure 12. Chemical structure of artemisinin (35) and postulated mechanism of its action.

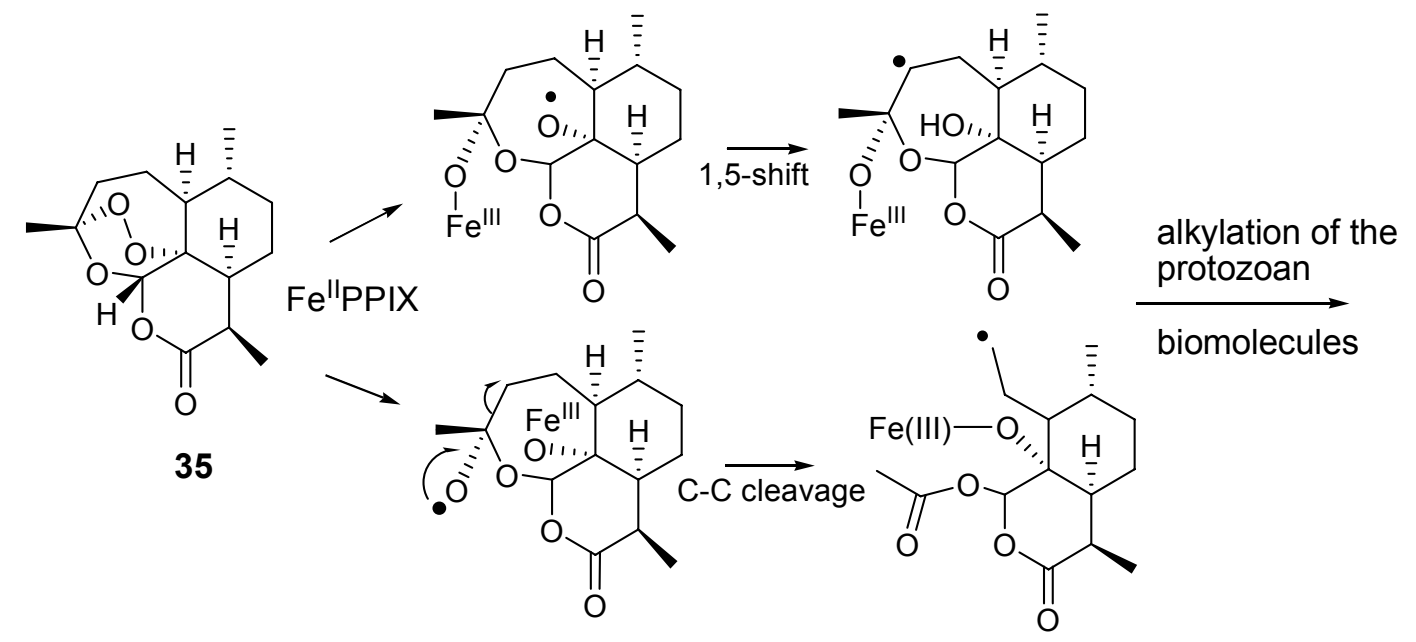

The endoperoxide linkage is an essential feature for antimalarial activity of artemisinin and of its derivatives (e.g. the oil-soluble artemether, the water-soluble artesunate). Indeed, according to the widely accepted mechanism of action, these molecule interact with the iron(II) center of the heme unit released during the digestion of hemoglobin. This yields to the cleavage of the peroxide bridge and to the consequent formation of oxygen-centered radicals which, after an intramolecular rearrangement, convert into free $\mathrm{C}$-centered radicals. These should be toxic to the parasite through alkylation of "sensitive" macromolecular targets (Figure 12). $\mathrm{A} \mathrm{Ca}^{2+}$-dependent ATPase specific of P. falciparum (PfATP6) has been suggested as a potential target for these active species [58].

Intense research activity is currently ongoing in many laboratories around the world in order to obtain from natural sources endoperoxide derivatives which could constitute a valuable alternative to artemisinin. In this context, the next two sections will provide a survey of the contribution in this field coming from marine chemists. For clarity, these molecules have been divided in two categories 
according to their postulated (and only in few cases unambiguously demonstrated) biogenetic origin: polyketides and terpenoids.

\subsection{Polyketides}

Marine sponges belonging to the family Plakinidae contain a series of simple endoperoxide derivatives that have been identified as polyketide metabolites possessing six- or five-membered 1,2dioxygenated rings (1,2-dioxane or 1,2-dioxolane, respectively). A further variation is represented, in some cases, by the presence of a 3-methoxy substitution, building a peroxyketal group.

Plakortin (36, Figure 13) was isolated more than 25 years ago from Plakortis halichondroides [59] and recently re-isolated in remarkable amounts from the Caribbean sponge Plakortis simplex [60]. In the latter study the absolute configuration of the four stereogenic carbons of plakortin has been determined by means of chemical derivatization and reaction with chiral auxiliaries. The plakortin analogues, dihydroplakortin (37), 3-epiplakortin (38), plakortide Q (39) (Figure 13) have been obtained from the same sponge $[60,61]$.

Figure 13. Chemical structures of plakortin (36) dihydroplakortin (37), 3epiplakortin (38), and plakortide Q (39).

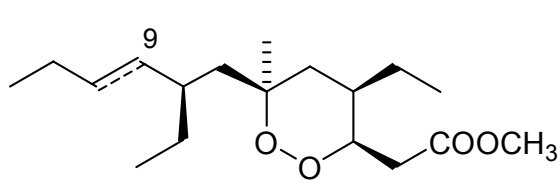

$36 \Delta^{9,10}$

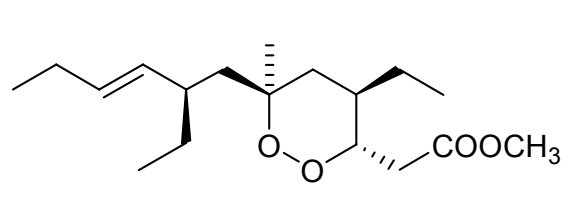

38

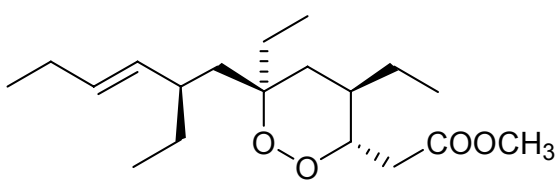

39

37

All these molecules exhibited a good antimalarial activity against D10, chloroquine-sensitive strain, and W2, chloroquine-resistant strain of $P$. falciparum, with a more potent activity on the W2 strain $\left(\mathrm{IC}_{50} \sim 180 \mathrm{ng} / \mathrm{mL}\right)$, devoid of cytotoxicity [62]. The chemical structure of these antimalarial leads is remarkably simple and they could constitute a good probe to investigate the mechanisms of action as well as structure-activity relationships. In this regard, a series of semisynthetic derivatives of plakortin (37) has been prepared [63] and their activity highlighted the crucial roles both of the "western" alkyl side chain and of the conformational behaviour of the dioxane ring in the light of the interaction with the heme planar target.

Furthermore, strong evidence have been gathered about the plakortin production by a bacterial symbiot of the sponge Plakortis simplex [64]. Hopefully, an approach based on identification, cloning and expression of the gene cluster(s) for plakortin and related compounds from the metagenome of the sponge could allow the production of plakortin by easy and low-cost bacterial fermentation, thus fulfilling one of the essential requirements of next generation antimalarial drugs.

Interestingly, plakortide L (40, Figure 14), isolated from a Jamaican sponge Plakortis sp. [65], plakortide $\mathrm{O}$ (41) and plakortide P (42), isolated from Plakortis halichondrioides [66], showed a very low in vitro antimalarial activity $\left(\mathrm{IC}_{50}>8 \mu \mathrm{g} / \mathrm{mL}\right)$, in spite of their similarity with the plakortin 
scaffold. The configurational changes around the dioxane ring and/or the differences in the alkyl side chains are evidently responsible for the marked decrease of activity.

Figure 14. Chemical structures of plakortides L (40), O (41) and P (42).
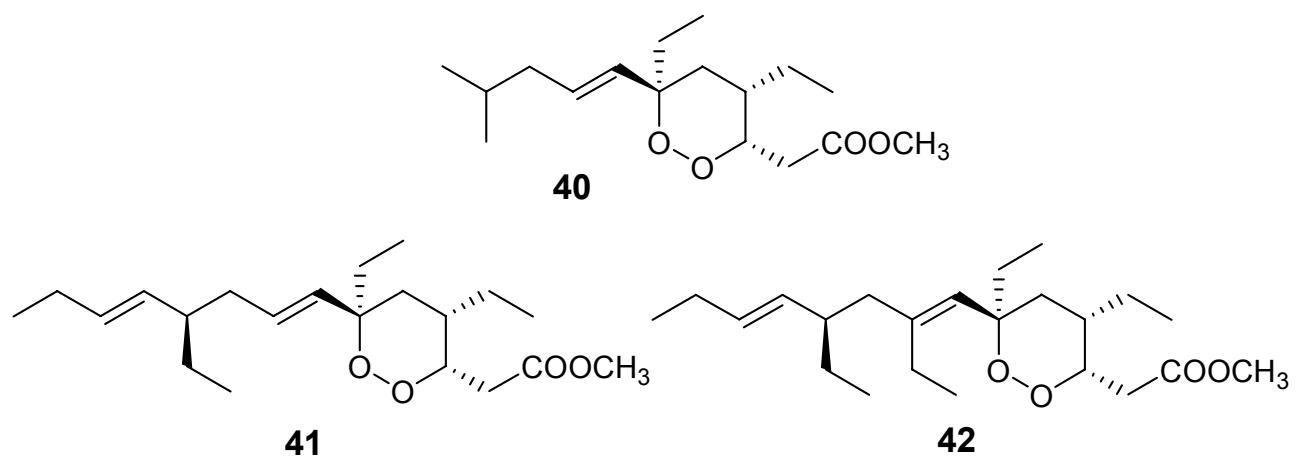

A structurally related class of marine metabolites showing a good antimalarial activity is that of 3alkoxy-1,2-dioxane (peroxyketals) derivatives. In this class of molecules, the alkoxy substituent at position 3 could partly mimic the non-peroxidic oxygen atom of the 1,2,4-trioxane ring of artemisinin. The methyl esters of peroxyplakoric acids $A_{3}$ (43, Figure 15) and $B_{3}$ (44, Figure 15) isolated from Plakortis sp., showed $\mathrm{IC}_{50}=50 \mathrm{ng} / \mathrm{mL}$ against $P$. falciparum with a good selective toxicity index (about 200) [67].

Figure 15. Chemical structures of peroxyplakoric acids $A_{3}(43)$ and $B_{3}(44)$ methyl esters, of chondrillin (47) and of two synthetic analogues (45 and 46).<smiles>CC/C=C/C=C/CCC[C@]1(C)CC[C@@H]([C@@H](C)COC)OO1</smiles>

43

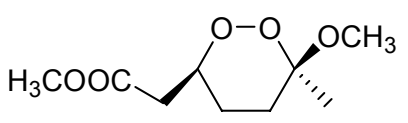

45<smiles>CC/C=C/C=C/CCC[C@]1(OC)CC[C@@H]([C@@H](C)COC)OO1</smiles>

44

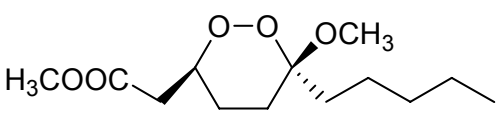

46

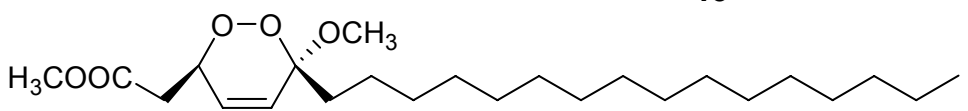

47

Through the syntheses of some analogues of these active compounds, some conclusions about the structural requirements within this class of antimalarials were drawn. For example, compound 45 (Figure 15) proved to be almost completely inactive, whereas compound 46 (Figure 15) retained the in vitro activity of peroxyplakoric acid $\mathrm{B}_{3}$ methyl ester, indicating the importance of the side chain for the antimalarial activity [68]. Furthermore, it has been demonstrated that the in vivo antimalarial potency of these compounds is increased by transforming the ester group into an amide group [69].

Finally, the low antimalarial activity observed for a marine endoperoxide strictly related to peroxyplakoric acid $\mathrm{B}_{3}$ methyl ester, namely chondrillin, (47, Figure 15) [70] indicates that the 
presence of a double bond within the 3-methoxy-1,2-dioxane skeleton is detrimental for the activity, although the role of the long saturated alkyl chain should also be taken into account.

\subsection{Terpenoids}

Unfortunately, very few endoperoxide-containing terpenoids isolated from marine sources have been tested for their antimalarial activity. Sigmosceptrellin A, (48, Figure 16), is a norsesterterpene derivative active against $P$. falciparum $\left(\mathrm{IC}_{50} \sim 450 \mathrm{ng} / \mathrm{mL}\right.$ ) [71]. Interestingly, the C-3 epimer of 48, named sigmosceptrellin B, (49) proved to possess an activity about four times lower in the same test [72]. This is a good demonstration of the importance of stereochemistry to determine the antimalarial activity in the series of 1,2-dioxane derivatives.

Figure 16. Chemical structures of sigmosceptrellin A (48) and of its C-3 epimer sigmosceptrellin B (49).

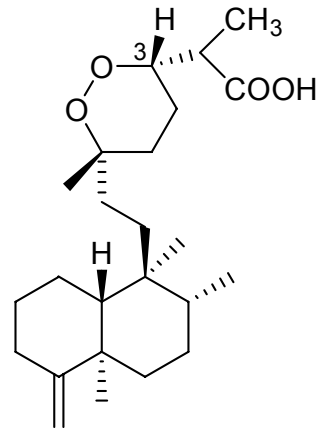

48

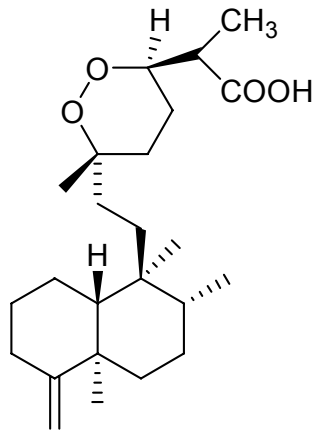

49

Methyl-3-epinuapapuanoate, (50, Figure 17), a norditerpene derivative isolated from the New Caledonian sponge Diacarnus levii [73], showed a moderate in vitro activity against chloroquineresistant strains of $P$. falciparum $\left(\mathrm{IC}_{50}=1.2 \mu \mathrm{g} / \mathrm{mL}\right.$ ) [74]. When the molecule was tested against $P$. berghei in vivo, at the concentration of $25 \mathrm{mg} / \mathrm{kg}$, a $56 \%$ growth inhibition was observed.

Figure 17. Chemical structure of methyl-3-epinuapapuanoate (50).

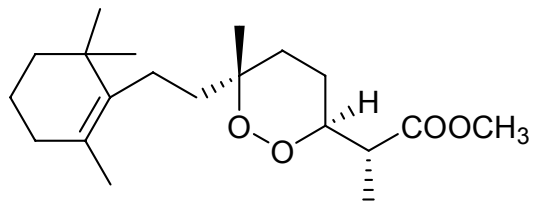

50

\section{Miscellaneous Compounds}

In this section we have grouped all the marine secondary metabolites endowed with antimalarial activity and not falling in one of the preceding groups, namely they do not contain an isonitrile or an endoperoxide group and they are not alkaloids. These molecules can be further divided into two structural categories, namely quinones and phenols, and peptides. 


\subsection{Quinones and Phenols}

In the frame of a search for Plasmodium protein kinase inhibitors, the previously known xestoquinone (51, Figure 18) [75] proved to be a selective active inhibitor of Pfnek-1, a never-inmitosis/Aspergillus (NIMA)-related protein kinase of P. falciparum [76]. However, the in vitro antiplasmodial activity of xestoquinone was moderate $\left(\mathrm{IC}_{50} \sim 3 \mu \mathrm{M}\right)$. A similar activity was exhibited by another marine quinone, ilimaquinone (52), isolated from the Australian marine sponge Dactylospongia elegans [77].

Figure 18. Chemical structures of xestoquinone (51) and ilimaquinone (52).<smiles>CC12CCCc3coc(c31)C(=O)c1cc3c(cc12)C(=O)C=CC3=O</smiles>

51<smiles></smiles>

52

A series of quinone derivatives, named alisiaquinones (e.g. alisiaquinone A, 53, Figure 19) structurally related to xestoquinone, have been isolated from an unidentified New Caledonian sponge [78]. Not surprisingly they showed an activity against Pfnek-1 and a micromolar antiplasmodial activity similar to those exhibited by xestoquinone. However, quite interestingly, alisiaquinone C (54), bearing an additional heterocycle formed by a taurine substituent, exhibited a submicromolar activity $\left(\mathrm{IC}_{50} \sim 0.1 \mu \mathrm{M}\right)$ on $P$. falciparum and a competitive selectivity index on the different plasmodial strains. This higher activity of alisiaquinone $C$ (54) resulted to be not related to a more potent inhibition of Pfnek-1 but to a significant inhibition of the plasmodial enzyme farnesyl transferase.

Figure 19. Chemical structure of alisiaquinones A (53) and C (54).<smiles></smiles>

53<smiles></smiles>

54

$(S)$-Curcuphenol (55, Figure 20) is a sesquiterpene phenol isolated from different marine sponges belonging to the genus Didiscus [79]. This molecule exhibited in vitro antimalarial activity with MIC of $3.6 \mu \mathrm{g} / \mathrm{mL}$ against the D6 clone of $P$. falciparum and of $1.8 \mu \mathrm{g} / \mathrm{mL}$ against the $\mathrm{W} 2$ clone. Another phenol-containing antimalarial marine metabolite is 15-oxopuupehenol (56), isolated from sponges of the genus Hyrtios, and representative of a distinctive family of sponge metabolites comprising also the quinol-quinone pair of avarol and avarone. Compound $\mathbf{5 6}$ exhibited in vitro activity against $P$. 
falciparum with MIC of $2.0 \mu \mathrm{g} / \mathrm{mL}$ against the D6 clone of $P$. falciparum and of $1.3 \mu \mathrm{g} / \mathrm{mL}$ against the W2 clone [80].

Figure 20. Chemical structures of cucurphenol (55) and 15-oxopuupehenol (56).<smiles>CC(C)=CCC[C@H](C)c1ccc(C)cc1O</smiles><smiles>CC1(C)CCC[C@@]2(C)C1CC[C@@]1(C)Oc3cc(O)c(O)cc3C(=O)C21</smiles>

\subsection{Peptides}

Two modified cyclic hexapeptides, venturamides (e.g. venturamide A, 57, Figure 21), isolated from the marine cyanobacterium Oscillatoria sp., exhibited a moderate activity against Plasmodium falciparum ( $\left.\mathrm{IC}_{50} \sim 6-7 \mu \mathrm{M}\right)$ [81], with a good selectivity.

A similar antimalarial profile was also exhibited by dragomabin (58, Figure 21), a linear alkynoic lipopeptide isolated from a Panamanian strain of the marine cyanobacterium Lyngbya majuscula [82]. Interestingly, the related non-aromatic dragonamide B (59, Figure 21), isolated from the same source, was completely devoid of activity.

A further cyanobacterial peptide derivative, named gallinamide A (60, Figure 21) has been isolated from Schizothrix species. This highly functionalized peptide, containing the very unusual 4-(S)-amino2-(E)-pentenoic acid subunit and an $N, N$-dimethyl isoleucine terminus, exhibited a moderate in vitro antimalarial activity $\left(\mathrm{IC}_{50}=8.4 \mu \mathrm{M}\right)[83]$.

Figure 21. Chemical structures of venturamide A (57), dragomabin (58), dragonamide B (59), and gallinamide A (60).

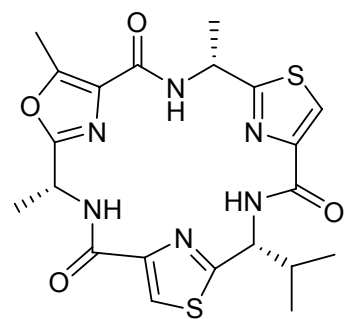

57<smiles>C#CCCCC[C@H](C)C(=O)N(C)[C@H](Cc1ccccc1)C(=O)N[C@@H](C)C(=O)N(C)[C@@H](C)C(=O)N(C)[C@@H](Cc1ccc(OC)cc1)C(N)=O</smiles><smiles>C#CCCCC[C@H](C)C(=O)N(C)C(C(=O)N(C)[C@H](C(=O)N(C)[C@H](C(=O)N(C)[C@@H](C(N)=O)C(C)C)C(C)C)C(C)C)C(C)C</smiles><smiles>CCC(C)C(C(=O)O[C@H](CC(C)C)C(=O)N[C@@H](CC(C)C)C(=O)N[C@@H](C)/C=C/C(=O)N1C(=O)C=C(OC)[C@H]1C)N(C)C</smiles> 
Finally, a secondary metabolite belonging to a completely different class, a polyether (61, Figure 22) obtained from the marine Streptomyces sp. H668, exhibited a significant in vitro antimalarial activity $\left(\mathrm{IC}_{50} \sim 150 \mathrm{ng} / \mathrm{mL}\right)$, with a good selectivity [84]. Some examples of non-marine antimalarial polyether compounds are also present in the literature [85]. These compounds are believed to act as ionophores, and, due to their lipophilic character they are particularly able to interact with the protozoan- infected cell membrane.

Figure 22. Chemical structure of the polyether 61.

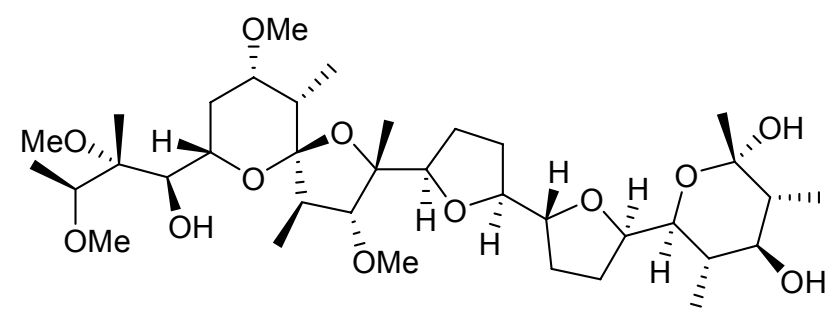

61

\section{Conclusions}

Data reported in the preceding paragraphs clearly demonstrate that the marine environment contains a number of compounds that could serve as lead structures for the development of new classes of antimalarial drugs. The antimalarial marine molecules can efficiently integrate the panel of lead compounds isolated from terrestrial sources (as in the case of endoperoxide derivatives) with new chemical backbones and, sometimes, with unique functional groups (as in the case of isonitrile derivatives). Of course, the drug potential of the about 60 molecules reported in this review is not the same, being related to the potency, to the selectivity, to the toxicity, and to the availability of the compounds. Among them, some isonitrile containing diterpenes, manzamines, salinosporamide, and some polyketide endoperoxides could be indicated as the most promising candidates to future developments. In this regard, the possibility of producing these molecules through bacterial fermentation combined with genetic engineering is a key issue to increase the chances of their full pharmacological evaluation and their possible introduction in therapy.

\section{References and Notes}

1. Data taken from Malaria Foundation International, http://www.malaria.org and linked sites. accessed on April 6, 2009.

2. Available online: http://www.who.int. (accessed on April 6, 2009).

3. Collins, W.E.; Barnwell, J.W. A hopeful beginning for malaria vaccines. N. Engl. J. Med. 2008, 359, 2599-2601.

4. Gardner, M.J.; Hall, N.; Fung, E.; White, O.; Berriman, M.; Hyman, R.W.; Calton, J.M.; Pain, A.; Nelson, K.E.; Bowman, S. Genome sequence of the human malaria parasite. Plasmodium falciparum. Nature 2002, 419, 498-511. 
5. Jefford, C.W. Why artemisinin and certain synthetic peroxides are potent antimalarials. Implications for the mode of action. Curr. Med. Chem. 2001, 15, 1803-1826.

6. Klayman, D.L. Qinghaosu (artemisinin): an antimalarial drug from China. Science 1985, 228, 1049-1055.

7. Bernan V.S. In Marine Chemical Ecology; McClintock, J.B., Baker, B.J. Eds., CRC Press: Boca Raton, FL, USA, 2001, pp. 567-592.

8. Hentschel, U. Natural products from marine microorganisms. Chem. Bio. Chem. 2002, 3, 1151-1154.

9. Salomon, C.E.; Magarvey, N.A.; Sherman, D.H. Merging the potential of microbial genetics with biological and chemical diversity: an even brighter future for marine natural product drug discovery. Nat. Prod. Rep. 2004, 21, 105-121.

10. Mancini, I.; Guella, G.; Defant, A. Synthesis of marine natural products with antimalarial activity. Mini-Rev. Med. Chem. 2008, 8, 1265-1284.

11. Fattorusso, E., Taglialatela-Scafati, O. In Studies in Natural Products Chemistry, vol. 32, Bioactive Natural Products (Part L) Atta-ur-Rahman Ed., Elsevier Pub.: Amsterdam, The Netherlands, 2005, pp. 169-207.

12. Cafieri, F.; Fattorusso, E.; Magno, S.; Santacroce, C.; Sica, D. Isolation and structure of axisonitrile 1 and axisothiocyanate 1, two unusual sesquiterpenoids from the marine sponge Axinella cannabina. Tetrahedron 1973, 29, 4259-4262.

13. Fattorusso, E.; Magno, S.; Mayol, L.; Santacroce, C.; Sica, D. Isolation and structure of axisonitrile 2. New sesquiterpenoid isonitrile from the sponge Axinella cannabina. Tetrahedron 1974, 30, 3911-3913.

14. Fattorusso, E.; Magno, S.; Mayol, L.; Santacroce, C.; Sica, D. New sesquiterpenoids from the sponge Axinella cannabina. Tetrahedron 1975, 31, 269-270.

15. Di Blasio, B.; Fattorusso, E.; Magno, S.; Mayol, L.; Pedone, C.; Santacroce, C.; Sica, D. Axisonitrile-3, axisothiocyanate-3 and axamide-3. Sesquiterpenes with a novel spiro[4,5]decane skeleton from the sponge Axinella cannabina. Tetrahedron 1976, 32, 473-478.

16. Kuo, Y.-L.; Dhanasekaran, M.; Sha, C.-K. Total Syntheses of Axamide-1 and Axisonitrile-1 via 6-Exo-dig Radical Cyclization. J. Org. Chem. 2009, 74, 2033-2038.

17. Angerhofer, C. K.; Pezzuto, J. M.; Koenig, G. M.; Wright, A. D.; Sticher, O. Antimalarial activity of sesquiterpenes from the marine sponge Acanthella klethra. J. Nat. Prod. 1992, 55, 1787-1789.

18. Koenig, G. M.; Wright, A. D.; Angerhofer, C. K.; Novel Potent Antimalarial diterpene isocyanates, isothiocyanates, and isonitriles from the tropical marine sponge Cymbastela hooperi. J. Org. Chem. 1996, 61, 3259-67.

19. Wright, A. D.; Lang-Unnasch, N. Diterpene Formamides from the Tropical Marine Sponge Cymbastela hooperi and Their Antimalarial Activity in Vitro. J. Nat. Prod. 2009, 72, 492-495.

20. Miyaoka, H.; Shimomura, M.; Kimura, H.; Yamada, Y.; Kim, H.S.; Wataya, Y. Antimalarial activity of kalihinol A and new relative diterpenoids from the Okinawan sponge, Acanthella sp., Tetrahedron 1998, 54, 13467-13474.

21. White, R.D.; Gregg, F.K.; Slown, C.D.; Wood, J.L. Total synthesis of ( $( \pm)-$ kalihinol C. Org. Lett. 2004, 6, 1123-1126. 
22. Wright, A.D.; Wang, H.; Gurrath, M.; Koenig, G.M.; Kocak, G.; Neumann, G.; Loria, P.; Foley, M.; Tilley, L. Inhibition of Heme Detoxification Processes Underlies the Antimalarial Activity of Terpene Isonitrile Compounds from Marine Sponges J. Med. Chem. 2001, 44, 873-885.

23. Sakai, R.; Higa, T.; Jefford, C.W.; Bernardinelli, G. Manzamine A, a novel antitumor alkaloid from a sponge. J. Am. Chem. Soc. 1986, 108, 6404-6405.

24. Peng, J.; Rao, Karumanchi V.; Choo, Y.M.; Hamann, M.T. In Modern Alkaloids. Fattorusso, E.; Taglialatela-Scafati, O., Eds; Wiley-VCH Pub.: Weinheim, Germany, 2008, pp. 189-232.

25. Yousaf, M.; El Sayed, K.A.; Rao, K.V.; Lim, C.W.; Hu, J.; Kelly, M.; Franzblau, S.G.; Zhang, F.; Peraud, O.; Hill, R.T.; Hamann, M.T. 12,34-Oxamanzamines, novel biocatalytic and natural products from manzamine producing Indo-Pacific sponges. Tetrahedron 2002, 58, 7397-7402.

26. Wypych, J.C.; Nguyen, T.M.; Nuhant, P.; Benechie, M.; Marazano, C. Further Insight from Model Experiments into a Possible Scenario Concerning the Origin of Manzamine Alkaloids Angew. Chem. Intl. Ed. 2008, 47, 5418-5421.

27. Ang, K.K.H.; Holmes, M.J.; Higa, T.; Hamann, M.T.; Kara, U.A.K. In vivo antimalarial activity of the .beta.-carboline alkaloid manzamine A. Antimicrob. Agent. Chemother. 2000, 44, 1645-1649.

28. Rao, K.V.; Donia, M.S.; Peng, J., Garcia-Palomero, E.; Alonso, D.; Martinez, A.; Medina, M.; Franzblau, S.G.; Tekwani, B.L.; Khan, S.I.; Wayhuono, S.; Willett, K.L.; Hamann, M.T. Manzamine B and E and Ircinal A Related Alkaloids from an Indonesian Acanthostrongylophora Sponge and Their Activity against Infectious, Tropical Parasitic, and Alzheimer's Diseases. J. Nat. Prod. 2006, 69, 1034-1040.

29. El Sayed, K. A.; Kelly, M.; Kara, U.A.K.; Ang, K.K.H.; Katsuyama, I.; Dunbar, D.C.; Khan, A.A.; Hamann, M.T. New manzamine alkaloids with potent activity against infectious diseases. $J$. Am. Chem. Soc. 2001, 123, 1804-1808.

30. Yousaf, M.; El Sayed, K.A.; Rao, K.V.; Lim, C.W.; Hu, J.; Kelly, M.; Franzblau, S.G.; Zhang, F.; Peraud, O.; Hill, R.T.; Hamann, M.T. 12,34-Oxamanzamines, novel biocatalytic and natural products from manzamine producing Indo-Pacific sponges. Tetrahedron 2002, 58, 7397-7402.

31. Shilabin, A.G.; Kasanah, N.; Tekwani, B.L.; Hamann, M.T. Kinetic Studies and Bioactivity of Potential Manzamine Prodrugs. J. Nat. Prod. 2008, 71, 1218-1221.

32. Yousaf, M.; Hammond, N.L.; Peng, J.; Wayhuono, S.; McIntosh, K.A.; Charman, W.N.; Mayer, A.M.S.; Hamann, M.T. New manzamine alkaloids from an Indo-Pacific sponge. Pharmacokinetics, oral availability, and the significant activity of several manzamines against HIV-I, AIDS opportunistic infections, and inflammatory diseases. J. Med. Chem. 2004, 47, 35123517.

33. Rao, K.V.; Santarsiero, B.D.; Mesecar, A.D.; Schinazi, R.F.; Tekwani, B.L.; Hamann, M.T. New manzamine alkaloids with activity against infectious and tropical parasitic diseases from an Indonesian sponge. J. Nat. Prod. 2003, 66, 823-828.

34. Hamann, M.T.; Alonso, D.; Martin-Aparicio, E.; Fuertes, A.; Perez-Puerto, J.; Castro, A.; Morales, S.; Navarro, M.L.; del Monte-Millan, M.; Medina, M.; Pennaka, H.; Balaiah, A.; Peng, J.; Cook, J.; Wahyuono, S.; Martinez, A. Glycogen Synthase Kinase-3 (GSK-3) Inhibitory Activity and Structure-Activity Relationship (SAR) Studies of the Manzamine Alkaloids. Potential for Alzheimer's Disease. J. Nat. Prod. 2007, 70, 1397-1405. 
35. Winkler, J.D.; Axten, J.M. The first total syntheses of ircinol A, ircinal A, and manzamines A and D. J. Am. Chem. Soc. 1998, 120, 6425

36. Martin, S.F.; Humphrey, J.M.; Ali, A.; Hillier, M.C. Enantioselective total syntheses of ircinal A and related manzamine alkaloids. J. Am. Chem. Soc. 1999, 121, 866-867.

37. Humphrey, J.; Liao, Y.; Ali, A.; Rein, T.; Wong, Y.-L.; Chen, H.-J.; Courtney, A.K.; Martin, S.F. Enantioselective total syntheses of manzamine A and related alkaloids. J. Am. Chem. Soc. 2002, $124,8584-8592$.

38. Kirsch, G.; Koeng, G.M.; Wright, A.D.; Kaminsky, R.A New Bioactive Sesterterpene and Antiplasmodial Alkaloids from the Marine Sponge Hyrtios cf. erecta. J. Nat. Prod. 2000, 63, 825-829.

39. Steffan, B. Lepadin A, a decahydroquinoline alkaloid from the tunicate Clavelina lepadiformis. Tetrahedron 1991, 42, 8729-8732.

40. Wright, A.D.; Goclik, E.; Koenig, G.M.; Kaminsky, R.J. Lepadins D.F. Antiplasmodial and Antitrypanosomal Decahydroquinoline Derivatives from the Tropical Marine Tunicate Didemnum sp. J. Med. Chem. 2002, 45, 3067-3072.

41. Tsuneki, H.; You, Y.; Toyooka, N.; Sasaoka, T.; Nemoto, H.; Dani, J.A.; Kimura, I. Marine alkaloids (-)-pictamine and (-)-lepadin B block neuronal nicotinic acetylcholine receptors. Biol. Pharm. Bull. 2005, 28, 611-614.

42. Li, G.; Hsung, R.P.; Slafer, B.W.; Sagamanova, I.K. Total Synthesis of (+)-Lepadin F. Org. Lett. 2008, 10, 4991-4994.

43. Kourany-Lefoll, E.; Pais, M.; Sevenet, T.; Guittet, E.; Montagnac, A.; Fontaine, C.; Guenard, D.; Adeline, M.T.; Debitus, C.; Phloeodictines A and B: new antibacterial and cytotoxic bicyclic amidinium salts from the new caledonian sponge, Phloeodictyon sp. J. Org. Chem. 1992, 57, 3832-3835.

44. Mancini, I.; Guella, G.; Sauvain, M.; Debitus, C.; Duigou, A.; Ausseil, F.; Menou, J.; Pietra, F. New 1,2,3,4-tetrahydropyrrolo[1,2-a]pyrimidinium alkaloids (phloeodictynes) from the New Caledonian shallow-water haplosclerid sponge Oceanapia fistulosa. Structural elucidation from mainly LC-tandem-MS-soft-ionization techniques and discovery of antiplasmodial activity. Org. Biomol. Chem. 2004, 2, 783-787.

45. Neubert, B.J.; Snider, B.B. Synthesis of $( \pm)$-Phloeodictine A1. Org. Lett., 2003, 5, 765-768.

46. Tymiak, A.A.; Rinehart, K.L. Constituents of morphologically similar sponges. Aplysina and Smenospongia species. Tetrahedron 1985, 41, 1039-1047.

47. Hu, J.; Schetz, J.A.; Kelly, M.; Peng, J.; Ang, K.K.H.; Flotow, H.; Leong, C.Y.; Ng, S.B.; Buss, A.D.; Wilkins, S.P.; Hamann, M.T. New antiinfective and human 5-HT 2 receptor binding natural and semisynthetic compounds from the Jamaican sponge Smenospongia aurea. J. Nat. Prod. 2002, 65, 476-480.

48. Lazaro, J.E.H.; Nitcheu, J.; Predicala, R.Z.; Mangalindan, G.C.; Nesslany, F.; Marzin, D.; Concepcion, G.P.; Diquet, B. Heptyl prodigiosin, a bacterial metabolite, is antimalarial in vivo and non-mutagenic in vitro. J. Nat. Tox. 2002, 11, 367-377.

49. Forenza, S.; Minale, L.; Riccio, R.; Fattorusso, E. New bromopyrrole derivatives from the sponge Agelas oroides. J. Chem. Soc.: Chem. Commun. 1971, 18, 1129-30. 
50. Aiello, A.; Fattorusso, E.; Menna, M.; Taglialatela-Scafati, O. In Modern Alkaloids. Structure, Isolation, Synthesis and Biology. Fattorusso, E.; Taglialatela-Scafati, O., Eds.; Wiley-VCH: Weinheim, Germany, 2007, pp. 271-304.

51. Tasdemir, D.; Topaloglu, B.; Perozzo, R.; Brun, R.; O'Neill, R.; Carballeira, N.M.; Zhang, X.; Tonge, P.J.; Linden, A.; Rueedi, P. Marine natural products from the Turkish sponge Agelas oroides that inhibit the enoyl reductases from Plasmodium falciparum, Mycobacterium tuberculosis and Escherichia coli. Bioorg. Med. Chem. 2007, 15, 6834-6845.

52. Feling, R.H.; Buchanan, G.O.; Mincer, T.J.; Kauffman, C.A.; Jensen, P.R.; Fenical, W. Salinosporamide A: a highly cytotoxic proteasome inhibitor from a novel microbial source, a marine bacterium of the new genus Salinispora. Angew. Chem., Int. Ed. 2003, 42, 355-357.

53. Prudhomme, J.; McDaniel, E.; Ponts, N.; Bertani, S.; Fenical, W.; Jensen, P.; Le Roch, K. Marine Actinomycetes: A New Source of Compounds against the Human Malaria Parasite. PLoS One 2008, 3, 2335.

54. Fukuda, T.; Sugiyama, K.; Arima, S.; Harigaya, Y.; Nagamitsu, T.; Omura, S. Total Synthesis of Salinosporamide. A. Org. Lett. 2008, 10, 4239-4242.

55. Takahashi, K.; Midori, M.; Kawano, K.; Ishihara, J.; Hatakeyama, S. Entry to heterocycles based on indium-catalyzed Conia-ene reactions: asymmetric synthesis of (-)-salinosporamide A. Angew. Chem., Int. Ed. 2008, 47, 6244-6246.

56. Klayman, D.L.; Lin, A.J.; Acton, N.; Scovill, J.P.; Hoch, J.M.; Milhous, W.K.; Theoharides, A.D.; Dobek, A.S. Isolation of artemisinin (qinghaosu) from Artemisia annua growing in the United States. J. Nat. Prod. 1984, 47, 715-717.

57. Avery, M.A.; Chong, W.K.M.; Jennings-White, C.; Stereoselective total synthesis of (+)artemisinin, the antimalarial constituent of Artemisia annua L. J. Am. Chem. Soc. 1992, 114, 974-979.

58. Eckstein-Ludwig, U.; Webb, R.J.; Van Goethem, I.D.A.; East, J.M.; Lee, A.G.; Kimura, M.; O’Neill, P.M.; Bray, P.G.; Ward, S.A.; Krishna, S.; Artemisinins target the SERCA of Plasmodium falciparum. Nature 2003, 424, 957-961.

59. Higgs, M.D.; Faulkner, D.J.; Plakortin, an antibiotic from Plakortis halichondrioides. J. Org. Chem. 1978, 43, 3454-3457.

60. Cafieri, F.; Fattorusso, E.; Taglialatela-Scafati, O.; Ianaro, A. Metabolites from the sponge Plakortis simplex. Determination of absolute stereochemistry of plakortin. Isolation and stereostructure of three plakortin related compounds. Tetrahedron 1999, 55, 7045-7056.

61. Campagnuolo, C.; Fattorusso, E.; Romano, A.; Taglialatela-Scafati, O.; Basilico, N.; Parapini, S.; Taramelli, D. Antimalarial polyketide cycloperoxides from the marine sponge Plakortis simplex. Eur. J. Org. Chem. 2005, 5077-5083.

62. Fattorusso, E.; Parapini, S.; Campagnuolo, C.; Basilico, N.; Taglialatela-Scafati, O.; Taramelli, D. Activity against Plasmodium falciparum of cycloperoxide compounds obtained from the sponge Plakortis simplex. J. Antimicrob. Chemother. 2002, 50, 883-888.

63. Fattorusso, C.; Campiani, G.; Catalanotti, B.; Persico, M.; Basilico, N.; Parapini, S.; Taramelli, D.; Campagnuolo, C.; Fattorusso, E.; Romano, A.; Taglialatela-Scafati, O. Endoperoxide Derivatives from Marine Organisms: 1,2-Dioxanes of the Plakortin Family as Novel Antimalarial Agents. J. Med. Chem. 2006, 49, 7088-7094. 
64. Laroche, M.; Imperatore, C.; Grozdanov, L.; Costantino, V.; Mangoni, A.; Hentschel, U.; Fattorusso, E. Cellular localization of secondary metabolites isolated from the Caribbean sponge Plakortis simplex. Marine Biol. 2006, 151, 1365-1373.

65. Hu, J.; Gao, H.; Kelly, M.; Hamann, M.T.; Plakortides K.-N. four new cyclic peroxides from an undescribed Jamaican sponge Plakortis sp. (Homosclerophorida, Plakinidae). Tetrahedron 2001, 57, 9379-9383.

66. Jimenez, M.D.S.; Garzon, S.P.; Rodriguez, A.D. Plakortides M and N, bioactive polyketide endoperoxides from the Caribbean marine sponge Plakortis halichondrioides. J. Nat. Prod. 2003, 66, 655-661. In this paper plakortides $\mathrm{O}$ and $\mathrm{P}$ were named plakortides $\mathrm{M}$ and $\mathrm{N}$, respectively, but their names were later corrected.

67. Kobayashi, M.; Kondo, K.; Kitagawa, I.; Antifungal peroxyketal acids from an Okinawan marine sponge of Plakortis sp. Chem. Pharm. Bull. 1993, 41, 1324-1326.

68. Murakami, N.; Kawanishi, M.; Itagaki, S.; Horii, T.; Kobayashi, M. New readily accessible peroxides with high antimalarial potency. Bioorg. Med. Chem. Lett. 2002, 12, 69-72.

69. Murakami, N.; Kawanishi, M.; Mostaqul, H.M.; Li, J.; Itagaki, S.; Horii, T.; Kobayashi, M.; New anti-malarial peroxides with In vivo potency derived from spongean metabolites. Bioorg. Med. Chem. Lett. 2003, 13, 4081-4084.

70. Quinoa, E.; Kho, E.; Manes, L.V.; Crews, P. Heterocycles from the marine sponge Xestospongia sp. J. Org. Chem. 1986, 51, 4260-4264.

71. El Sayed, K.A.; Dunbar, D.C.; Goins, D.K.; Cordova, C.R.; Perry, T.L.; Wesson, K.J.; Sanders, S.C.; Janus, S.A.; Hamann, M.T. The marine environment: A resource for prototype antimalarial agents. J. Nat. Toxins 1996, 5, 261-285.

72. El Sayed, K.A.; Hamann, M.T.; Hashish, N.E.; Shier, W.T.; Kelly, M.; Khan, A.A. Antimalarial, antiviral, and antitoxoplasmosis norsesterterpene peroxide acids from the Red Sea sponge Diacarnus erythraeanus. J. Nat. Prod. 2001, 64, 522-524.

73. D'Ambrosio, M.; Guerriero, A.; Debitus, C.; Waikedre, J.; Pietra, F. Relative contributions to antitumoral activity of lipophilic vs. polar reactive moieties in marine terpenoids. Tetrahedron Lett. 1997, 38, 6285-6288.

74. D'Ambrosio, M.; Guerriero, A.; Deharo, E.; Debitus, C.; Munoz, V.; Pietra, F. New types of potentially antimalarial agents. Epidioxy-substituted norditerpene and norsesterterpenes from the marine sponge Diacarnus levii. Helv. Chim. Acta. 1998, 81, 1285-1292.

75. Nakamura, H.; Kobayashi, J.; Kobayashi, M.; Ohizumi, Y.; Hirata, Y. Physiologically active marine natural products from Porifera. VII. Xestoquinone. A novel cardiotonic marine natural product isolated from the Okinawan sea sponge Xestospongia sapra. Chem. Lett. 1985, 6, 713-16.

76. Laurent, D.; Jullian, V.; Parenty, A.; Knibiehler, M.; Dorin, D.; Schmitt, S.; Lozach, O.; Lebouvier, N.; Frostin, M.; Alby, F.; Maurel, S.; Doerig, C.; Meijer, L.; Sauvain, M. Antimalarial potential of xestoquinone, a protein kinase inhibitor isolated from a Vanuatu marine sponge Xestospongia sp. Bioorg. Med. Chem., 2006, 14, 4477-4482.

77. Goclik, E.; Konig, G.M.; Wright, A.D.; Kaminsky, R. Pelorol from the tropical marine sponge Dactylospongia elegans. J. Nat. Prod., 2000, 63, 1150-1154.

78. Desoubzdanne, D.; Marcourt, L.; Raux, R.; Chevalley, S.; Dorin, D.; Doerig, C.; Valentin, A.; Ausseil, F.; Debitus, C. Alisiaquinones and Alisiaquinol, Dual Inhibitors of Plasmodium 
falciparum Enzyme Targets from a New Caledonian Deep Water Sponge. J. Nat. Prod. 2008, 71, 1189-1192.

79. El Sayed, K. A.; Yousaf, M.; Hamann, M. T.; Avery, M. A.; Kelly, M.; Wipf, P.; Microbial and Chemical Transformation Studies of the Bioactive Marine Sesquiterpenes (S)-(+)-Curcuphenol and -Curcudiol Isolated from a Deep Reef Collection of the Jamaican Sponge Didiscus oxeata. $J$. Nat. Prod. 2002, 65, 1547-1553.

80. Nasu, S.S.; Yeung, B.K.S.; Hamann, M.T.; Scheuer, P.J.; Kelly-Borges, M.; Goins, K. Puupehenone-related metabolites from two Hawaiian sponges, Hyrtios spp. J. Org. Chem. 1995, 60, 7290-7292.

81. Linington, R.G.; Gonzalez, J.; Urena, L.-D.; Romero, L.I.; Ortega-Barria, E.; Gerwick, W.H. Venturamides A and B: Antimalarial Constituents of the Panamanian Marine Cyanobacterium Oscillatoria sp. J. Nat. Prod. 2007, 70, 397-401.

82. McPhail, K.L.; Correa, J.; Linington, R.G.; Gonzalez, J.; Ortega-Barria, E.; Capson, T.L.; Gerwick, W.H. Antimalarial Linear Lipopeptides from a Panamanian Strain of the Marine Cyanobacterium Lyngbya majuscula. J. Nat. Prod. 2007, 70, 984-988.

83. Linington, R.G.; Clark, B.R.; Trimble, E.E.; Almanza, A.; Urena, L.-D.; Kyle, D.E.; Gerwick, W.H. Antimalarial peptides from marine cyanobacteria: Isolation and structural elucidation of gallinamide A. J. Nat. Prod. 2009, 72, 14-17.

84. Na, M.; Meujo, D.A.F.; Kevin, D.; Hamann, M.T.; Anderson, M.; Hill, R.T.A new antimalarial polyether from a marine Streptomyces sp. H668. Tetrahedron Lett. 2008, 49, 6282-6285.

85. Otoguro, K.; Ishiyama, A.; Ui, H.; Kobayashi, M.; Manabe, C.; Yan, G.; Takahashi, Y.; Tanaka, H.; Yamada, H.; Omura, S. In vitro and in vivo antimalarial activities of the monoglycoside polyether antibiotic, K-41 against drug resistant strains of Plasmodia. J. Antibiot. 2002, 55, 832-834.

(C) 2009 by the authors; licensee Molecular Diversity Preservation International, Basel, Switzerland. This article is an open-access article distributed under the terms and conditions of the Creative Commons Attribution license (http://creativecommons.org/licenses/by/3.0/). 